\title{
Incidental gallbladder cancer: Missing links in Pakistani population
}

\author{
Sajid Muhammad Tanveer, Hussain Syed Mukarram, \\ Hashmi Shoaib Nayyar, Mustafa Qurat Ul Ain, Shaheen Neelofar
}

\section{ABSTRACT}

Aims: To determine frequency of incidental gallbladder cancer (IGBC) in Pakistani population, its demographic/histopathological features and type of surgical resections performed. Methods: This observational study was conducted at Combined Military Hospital (CMH)/Armed Forces Institute of Pathology (AFIP) Rawalpindi, Pakistan from July 2009 to July 2015. Clinical as well as pathological records of all patients who underwent laparoscopic cholecystectomy (LC) / open cholecystectomy (OC) were reviewed and data was obtained regarding IGBC and benign gallbladder pathology. Patients diagnosed

Sajid Muhammad Tanveer ${ }^{1}$, Hussain Syed Mukarram², Hashmi Shoaib Nayyar ${ }^{3}$, Mustafa Qurat UI Ain ${ }^{4}$, Shaheen Neelofar ${ }^{5}$

Affiliations: ${ }^{1}$ MBBS, FCPS, Assistant Professor \& Classified Surgical Specialist, Department of General and Laparoscopic surgery, Combined Military Hospital Rawalpindi, Punjab, Pakistan; ${ }^{2}$ MBBS, FCPS, Associate Professor \& Head of Department, Department of General and Laparoscopic Surgery, Combined Military Hospital Rawalpindi, Punjab, Pakistan; ${ }^{3}$ MBBS, FCPS, FRCP, Professor \& Head of Department, Department of Histopathology, Armed Forces Institute of Pathology, Rawalpindi, Pakistan; ${ }^{4} \mathrm{MBBS}$, Senior Registrar, Department of Chemical Pathology, Armed Forces Institute of Pathology, Rawalpindi, Pakistan; ${ }^{5}$ MBBS, Senior Medical Officer, Department of General and Laparoscopic Surgery, Combined Military Hospital Rawalpindi, Punjab, Pakistan.

Corresponding Author: Muhammad Tanveer Sajid, C/o Hafiz Ghulam Mustafa Ezzy traders Hakeem jee building Jinnah road Abbottabad, KPK, Pakistan, 22010; Email: doc_tanveersajid@hotmail.com

Received: 02 April 2016

Accepted: 22 June 2016

Published: 23 February 2017 with cancer underwent staging investigations and were offered definitive surgery. Overall frequency and clinicopathological features of IGBC were studied. Results: One hundred sixtyfour patients out of 10,549 had IGBC (1.55\%). Mean age of presentation in IGBC and benign gallbladder pathology patients was $59.23 \pm 12.17$ and $45 \cdot 73 \pm 13.11$ years respectively (p-value <0.001). Cancer patients had significantly more comorbid $(73.17 \%$ versus $39.43 \%$, p-value $<0.001)$ and larger stones (p-value <0.001). Histopathology revealed adenocarcinoma in 148 (90.24\%), adenosquamous carcinoma in 08 (4.88\%), undifferentiated in $04(2.44 \%)$, squamous cell carcinoma in $02(1.22 \%)$, sarcoma and melanoma in one patient each (0.61\%). Most of the tumors were well differentiated (36.59\%) and liver was most commonly infiltrated organ (52.44\%). Thirty-four patients had stage I, 38 patients had stage II, 49 patients had stage III and 43 patients had stage IV cancer $(20.73 \%$, 23.17\%, 29.88\%, 26.22\% respectively). Surgical resection included no further treatment in 31 patients as cholecystectomy proved adequate vis-à-vis stage, extended cholecystectomy in three patients $(1.83 \%)$, radical cholecystectomy in $17(10.37 \%)$, pancreaticoduodenectomy (Whipple) in 6 (3.66\%), palliation/symptomatic management in $42(25.61 \%)$ patients while 65 (39.63\%) patients refused surgery. Adequate lymphadenectomy was performed only in 50 (30.49\%) patients while $44(26.83 \%)$ showed positive resection margins. Conclusion: IGBC must be kept in mind while performing cholecystectomy and every specimen should undergo routine histopathological examination. Radical surgery should be offered and may improve outcome in carefully selected cases.

Keywords: Benign pathology, Cholecystectomy, Incidental gallbladder cancer, Radical cholecystectomy 


\section{How to cite this article}

Tanveer SM, Mukarram HS, Nayyar HS, Ul Ain MQ, Neelofar S. Incidental gallbladder cancer: Missing links in Pakistani population. Int $\mathrm{J}$ Hepatobiliary Pancreat Dis 2017;7:1-10.

Article ID: 100065IJHPDST2017

$* * * * * * * * *$

doi:10.5348/ijhpd-2017-65-OA-1

\section{INTRODUCTION}

Gallbladder cancer (GBC), a highly lethal disease, is the third most prevalent gastrointestinal tract cancer with multifactorial etiology [1]. Strikingly distinct ethnic, gender and geographical variations superimpose vague clinical picture, leading to late diagnosis at advance stage usually in the seventh decade and disastrous clinical course with dismal survival rates, in spite of growing awareness and recent advances in medical sciences [2].

Global rates for GBC exhibit striking variability closely following worldwide prevalence of gallstones, reaching epidemic levels for Mapuche Indians of Chile (35/100000) followed by Hispanics, North American, Indians, and Japanese [3]. Asian subcontinent exhibits extraordinarily high disease incidence, where an increased frequency of GBC occurs in north Indian females (21.5/10000o), Pakistani females (13.8/100000) and Korean males [4].

Adenoma-carcinoma sequence and dysplasiacarcinoma sequence are the most common theories as exact etiology of GBC is still not known. Intrinsic genetic predisposition orchestrated by environmental triggers play critical role in eliciting cancer [5]. Gallstones represent most significant risk factor being present in $85 \%$ cases [6]. Progression is frequently rapid and silent with early spread through vascular, lymphatic, intraperitoneal, neural and intraductal routes, most common route being lymphatics. Metastases usually occur in liver, adjacent organs and peritoneum, liver being involved in $76-86 \%$ cases [7].

Significant overlap between benign gallbladder pathology and GBC defies early detection leading to incidental diagnosis in majority at advanced stage. Persistent right upper quadrant pain, jaundice, anorexia, nausea and weight loss are most common symptoms while palpable gallbladder is present in a few only. Deranged liver functions represent most common laboratory finding [8]. Though ultrasonography (USG) is most widely used initial screening as well diagnostic tool, it lacks sensitivity and specificity for early cancer. Other preferred investigations are endoscopic ultrasound
(EUS), computed tomography (CT) scan, magnetic resonance cholangiopancreatography (MRCP) and fluorodeoxyglucose positron emission tomography (FDG-PET) [9]. Although there is currently no single tumor marker helping clinch diagnosis, promising one include cancer antigen (CA) 242, CA-125, and CA-19-9.

Clinical and pathological staging is most important determinant dictating treatment strategy and outcome. Adenocarcinoma is the most common histopathological type and immunohistochemistry helps differentiate difficult cases [10]. Early diagnosis and radical surgical resection offers only chance of long-term survival. Unfortunately, only $10 \%$ or so are resectable at the time of diagnosis. Incidental gallbladder cancer may be defined as a malignancy detected only on histopathological examination without prior preoperative suspicion of malignancy. Current study was performed to determine frequency of IGBC in Pakistani population, its demographic as well as histopathological features and type of surgical resections performed.

\section{MATERIALS AND METHODS}

After approval of Hospital Ethical Committee, clinical as well as pathological records of all patients who underwent laparoscopic cholecystectomy (LC)/open cholecystectomy (OC) at hepatobiliary department $\mathrm{CMH} /$ AFIP Rawalpindi, a tertiary care referral center, from July 2009 till December 2015, were studied. Incidental gallbladder cancer was defined as a malignancy detected only on histopathological examination without prior preoperative suspicion of malignancy. Only those cases having complete clinical as well as pathological record were included.

Gallbladder disease was confirmed through history, physical examination, laboratory tests and USG. Choledocholithiasis was treated with preoperative endoscopic retrograde cholangiopancreatography (ERCP) and sphincterotomy/stenting after confirmation of diagnosis with MRCP/CT scan while gallstone pancreatitis was also treated with LC in the same admission after settlement of acute pancreatitis. Laparoscopic cholecystectomy was initial procedure and converted to open when indicated or felt appropriate. Patients diagnosed with IGBC on histopathological examination underwent staging investigations and were staged according to 7 th edition of the American Joint Committee on Cancer (AJCC) Manual, 2010 [11]. Second stage surgical resection was offered to those patients having stage II/III disease if Ro was deemed possible while simple cholecystectomy was considered sufficient for Tis/T1a disease and palliative care offered for stage IV disease. Extended cholecystectomy comprising of cholecystectomy, resection of $2 \mathrm{~cm}$ non-neoplastic liver tissue and skeletonization of hepatoduodenal ligament was performed in patients having $\mathrm{T} 1 \mathrm{~b}$ lesions. Radical cholecystectomy consisting cholecystectomy, 
excision of medial liver segments $4 \mathrm{~b} / 5$ and regional lymphadenectomy was carried out in $\mathrm{T}_{2}$ lesions while $\mathrm{T}_{3}$ lesions underwent removal of additional extra hepatic bile ducts or other organs as dictated by tumor spread. Palliation involved nonsurgical/surgical biliary drainage and symptomatic relief accordingly [12]. Definitive surgery was performed by same surgical team comprising two consultants and five registrars.

Analysis was carried out on formalin fixed and paraffin embedded (FFPE) tissue specimens by single consultant over the period of the study as per college of American pathologist (CAP) protocol version 3.1.0.2. Immunohistochemistry (IHC) help was sought in difficult cases and Leica Microsystems $®$, USA Cytokeratin (CK) 7 and 20 were employed. CK 7 positivity while CK 20 negativity confirmed GBC [13]. Cases diagnosed with IGBC were discussed in multidisciplinary team (MDT) meeting comprising operating surgeon, histopathologist, gastroenterologist and oncologist.

All the data reviewed was entered into Statistical Package for Social Sciences (SPSS) software version 21 for windows (SPSS Inc., Chicago, IL, USA) and analyzed through its statistical package. Mean \pm SD was used for quantitative data like age while frequency and percentage was calculated for qualitative data. Chi-square and t-test were applied for categorical and numerical variables respectively. P-value of less than $<0.05$ was taken as significant.

\section{RESULTS}

Clinical as well as pathological records of 12578 patients were reviewed with regard to demographic/ histopathological features and surgical intervention performed. Complete data was available in 10549 (83.87\%) patients and were included in analysis. Out of 10549 patients 164 (1.55\%) patients had IGBC. Mean age of presentation in IGBC and benign gallbladder pathology patients was $59.23 \pm 12.17$ and $45.73 \pm 13.11$ years respectively (p-value <0.001). Male: female ratio was 1:2.3 in IGBC and 1:3.2 in benign gallbladder pathology patients (p-value 0.042). Significantly more patients had concomitant disease in cancer group (73.17\% versus $39.43 \%$, p-value <0.001). BMI was also significantly high in cancer patients $(29.73 \pm 3.44$ IGBC and 28.19 \pm 3.99 benign gallbladder pathology, p-value $<0.001)$. Higher ASA status was found in cancer patients which may be due to presence of comorbid/ advance age (p-value <0.001). Single stone was present in 61(37.2\%) patients while multiple stones inflicted 91 (55.49\%) cancer patients. Size of stone was significantly larger in IGBC patients $(2.23 \pm 1.36 \mathrm{~cm}$ versus $1.27 \pm 0.66 \mathrm{~cm}$ $\mathrm{p}$-value <0.001). Most of the surgeries were performed by consultants while acute cholecystitis and symptomatic cholelithiasis were most common presenting pathologies is given in Table 1.
One hundred and sixty-four patients (114 females and 50 males) were diagnosed histologically with IGBC. Among them, 93 (56.71\%) patients presented with acute cholecystitis while 64 (39.02\%) with symptomatic cholelithiasis and 07 (4.27\%) had polyps. Majority had acute presentation while in 18 patients, length of disease was not known. Anorexia was the most common sinister symptom present in $53(32.32 \%)$ patients followed by
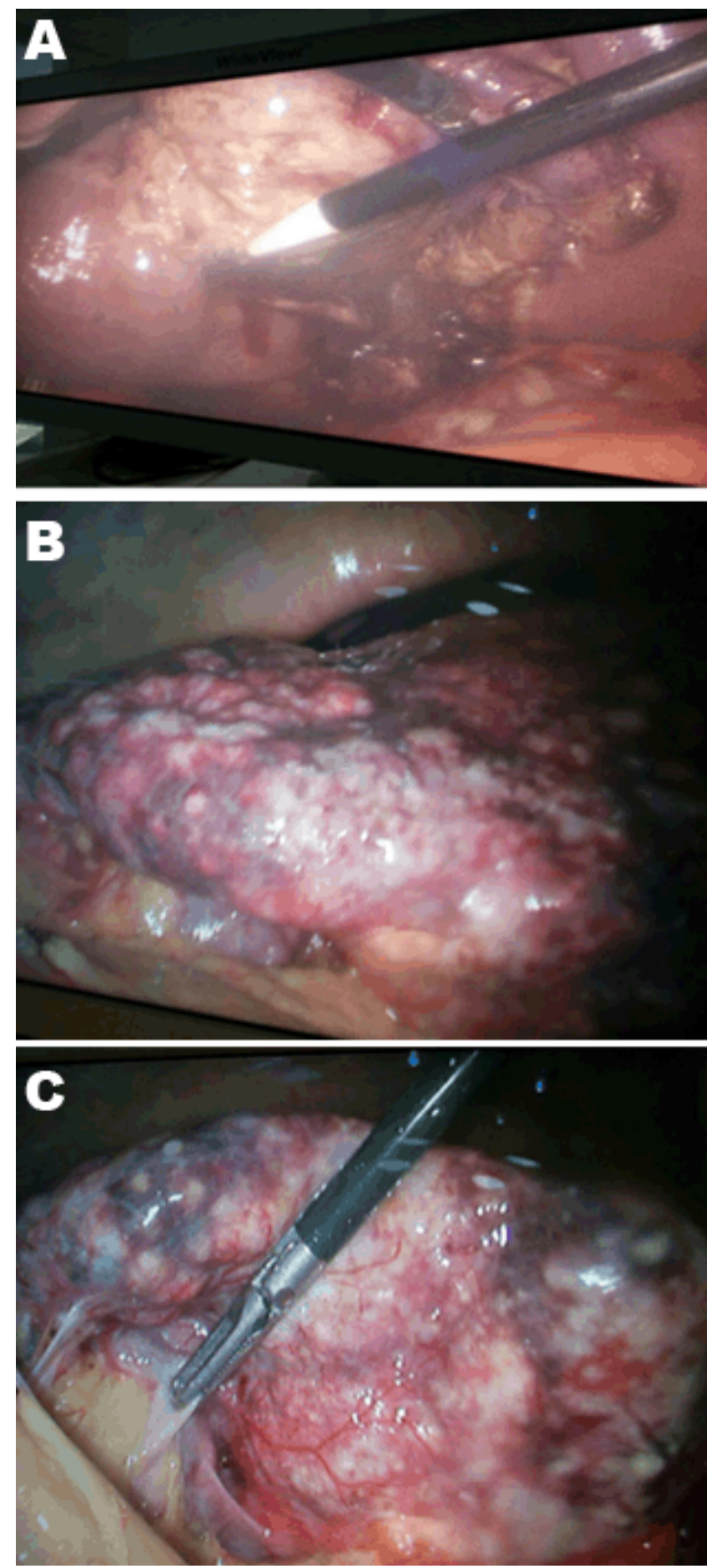

Figure 1: (A-C) Laparoscopic view of advance gallbladder cancer involving peritoneum and liver. Biopsy performed that revealed poorly differentiated adenocarcinoma. 
weight loss in $52(31.71 \%)$ and jaundice in 19 (11.59\%) patients. Family history of cancer was more commonly found in female patients. Significantly more smokers with cancer were diagnosed as males ( $p$-value $<0.001$ ). Simple cholecystectomy was performed in $72.81 \%$ while rest underwent biopsy only due to intraoperative suspicion (Figure 1) (Table 2).

Histopathological analysis revealed adenocarcinoma in 148 (90.24\%) patients, adenosquamous carcinoma in 8 (4.88\%), undifferentiated in $4(2.44 \%)$, squamous cell carcinoma in $02(1.22 \%)$, sarcoma and melanoma in one patient each (0.61\%). Fundus (42.1\%) of gallbladder was most common site followed by body and neck. Most of tumors were well differentiated (36.59\%) while $33.54 \%$ had poorly differentiated tumors. IHC was performed in 65 (39.63\%) patients to reach at correct diagnosis. Thirty four patients had stage I (31 patients Tis/T1a while three patients had T1b lesion), 38 patients had stage II, 49 patients had stage III and 43 patients had stage IV cancer $(20.73 \%, 23.17 \%, 29.88 \%, 26.22 \%$ respectively) according to AJCC 7th edition. Surgical resection included no further treatment in 31 patients, extended cholecystectomy in $3(1.83 \%)$, radical cholecystectomy in 17 (10.37\%), pancreaticoduodenectomy (Whipple) in 6 (3.66\%), palliation/symptomatic management in 42 (25.61\%) patients while 65 (39.63\%) patients refused any

Table 1: Demographic variables of incidental gallbladder cancer and benign gallbladder pathology patients

\begin{tabular}{|c|c|c|c|c|c|}
\hline \multirow[t]{2}{*}{ Characteristics } & \multicolumn{2}{|c|}{ Incidental gallbladder cancer } & \multicolumn{2}{|c|}{ Benign Pathology } & \multirow[t]{2}{*}{ p-value } \\
\hline & Frequency & Percentage & Frequency & Percentage & \\
\hline Male & 50 & 30.5 & 2457 & 23.66 & \\
\hline Female & 114 & 69.5 & 7928 & 76.34 & 0.042 \\
\hline Male :female ratio & \multicolumn{2}{|c|}{$1: 2.3$} & \multicolumn{2}{|c|}{$1: 3.2$} & \\
\hline Age in years & \multicolumn{2}{|c|}{$59.23 \pm 12.17$} & \multicolumn{2}{|c|}{$45 \cdot 73 \pm 13.11$} & 0.000 \\
\hline Concomitant disease & \multicolumn{2}{|c|}{$73.17 \%$} & \multicolumn{2}{|c|}{$39.43 \%$} & \\
\hline Diabetes mellitus & 71 & $43 \cdot 3$ & 1575 & 14.88 & \\
\hline Hypertension & 34 & 20.7 & 1890 & 17.86 & 0.000 \\
\hline Ischemic heart disease & 14 & 8.5 & 420 & 3.97 & \\
\hline Respiratory disease & 01 & 0.6 & 210 & 1.98 & \\
\hline \multicolumn{6}{|l|}{ Surgeon } \\
\hline Consultant & 115 & 70.1 & 7151 & 68.86 & 0.729 \\
\hline Resident & 49 & 29.9 & 3234 & 31.14 & \\
\hline Body Mass Index & \multicolumn{2}{|c|}{$29.73 \pm 3.44$} & \multicolumn{2}{|c|}{$28.19 \pm 3.99$} & 0.000 \\
\hline \multicolumn{6}{|l|}{ ASA status } \\
\hline I/II & 91 & $55 \cdot 5$ & 9305 & 89.6 & 0.000 \\
\hline III/IV & 73 & 44.5 & 1080 & 10.4 & \\
\hline \multicolumn{6}{|l|}{ Surgical anatomy } \\
\hline Single stone & 61 & 37.2 & 1134 & 10.92 & 0.000 \\
\hline Multiple stone & 91 & $55 \cdot 48$ & 6689 & 64.41 & \\
\hline Size of the stone & \multicolumn{2}{|c|}{$2.23 \pm 1.36$} & \multicolumn{2}{|c|}{$1.27 \pm 0.66$} & 0.000 \\
\hline \multicolumn{6}{|l|}{ Pre Op diagnosis } \\
\hline Ac cholecystitis & 93 & 56.7 & 1638 & $15 \cdot 77$ & \\
\hline Symptomatic cholelithiasis & 64 & 39 & 8117 & 78.16 & 0.000 \\
\hline Polyp & 07 & $4 \cdot 3$ & 105 & 1.01 & \\
\hline Other & o & 0 & 525 & 5.06 & \\
\hline
\end{tabular}

sort of surgical intervention. Liver was the most common organ to be involved by tumor (86 subjects $52.44 \%$ ). Only 50 patients (30.49\%) had adequate number of lymph node sent while in majority (55.49\%) no comment was found in histopathology report. Resection margins were positive in 44 (26.83\%) specimens while in 48 (29.27\%) patients, margin status was not mentioned (Table 3 ).

\section{DISCUSSION}

Gallbladder cancer is a highly lethal disease harboring dismal outcome. Cancer epidemiology (frequencies, pattern of distribution and determinants) are of immense importance as identification of risk factors provides insight into pathogenesis thus establishing platform for effective preventive and treatment strategies [14]. Early diagnosis and radical surgical resection is the only 
Table 2: Clinical features of incidental gallbladder cancer patients with respect to gender

\begin{tabular}{|c|c|c|c|c|c|}
\hline \multirow[t]{2}{*}{ Characteristics } & \multicolumn{2}{|c|}{ Male } & \multicolumn{2}{|c|}{ Female } & \multirow[t]{2}{*}{ p-value } \\
\hline & Frequency & Percentage & Frequency & Percentage & \\
\hline \multicolumn{6}{|l|}{ Clinical Presentation } \\
\hline Acute cholecystitis & 27 & 54 & 66 & 57.89 & \multirow{3}{*}{0.87} \\
\hline Symptomatic cholelithiasis & 21 & 42 & 43 & 37.72 & \\
\hline Polyp & 2 & 4 & 5 & 4.39 & \\
\hline \multicolumn{6}{|l|}{ Duration of cholelithiasis } \\
\hline$<10$ years & 27 & 54 & 65 & 57 & \multirow{3}{*}{0.92} \\
\hline$>10$ years & 17 & 34 & 37 & 32.46 & \\
\hline Not Known & 6 & 12 & 12 & 10.53 & \\
\hline \multicolumn{6}{|l|}{ Sinister symptoms } \\
\hline Anorexia & 15 & 30 & 38 & $33 \cdot 33$ & 0.67 \\
\hline Jaundice & 6 & 12 & 13 & 11.40 & 0.91 \\
\hline Weight loss & 15 & 30 & 37 & 32.46 & 0.76 \\
\hline \multicolumn{6}{|l|}{ Family history } \\
\hline Yes & 4 & 8 & 27 & 23.68 & \multirow[t]{2}{*}{0.18} \\
\hline No & 46 & 92 & 87 & 76.32 & \\
\hline \multicolumn{6}{|l|}{ Parity } \\
\hline Nulliparous & & & 5 & 4.39 & \\
\hline Multipara & & & 109 & 95.61 & \\
\hline \multicolumn{6}{|l|}{ Smoking } \\
\hline Yes & 42 & 84 & 13 & 11.4 & \multirow[t]{2}{*}{0.000} \\
\hline No & 8 & 16 & 101 & 88.6 & \\
\hline \multicolumn{6}{|l|}{ Surgical procedure } \\
\hline Simple cholecystectomy & 38 & 6 & 83 & 72.81 & \multirow[t]{2}{*}{0.67} \\
\hline Biopsy & 12 & 24 & 31 & 27.19 & \\
\hline \multicolumn{6}{|l|}{ Suspicion of cancer during } \\
\hline No & 12 & 24 & 31 & 27.19 & \multirow{2}{*}{0.67} \\
\hline Yes & & & & & \\
\hline \multicolumn{6}{|l|}{ Year wise cancer case } \\
\hline 2009 & 3 & 6 & 12 & 10.53 & \multirow{7}{*}{0.39} \\
\hline 2010 & 4 & 8 & 16 & 14.03 & \\
\hline 2011 & 4 & 8 & 15 & 13.16 & \\
\hline 2012 & 6 & 12 & 16 & 14.03 & \\
\hline 2013 & 9 & 18 & 15 & 13.16 & \\
\hline 2014 & 12 & 24 & 17 & 14.91 & \\
\hline 2015 & 12 & 24 & 23 & 20.18 & \\
\hline
\end{tabular}

effective weapon in treatment armamentaria at present [15].

Incidental gallbladder cancer is a realistic hope allowing considerable leverage of tactical maneuverability as disease stage is the most important determinant of surgical success [16]. Diagnosis of IGBC remains enigma due to paucity of clinical features and inability of investigations to identify the disease [17]. Recognizing important risk factors and associated clinical jargons may provide clue for picking IGBC early [18].

Current study focuses on frequency of IGBC at tertiary care referral center, its demographic/histopathological variables and overview of definitive surgeries performed. Clinical as well as pathological record of 10549 patients was studied. Incidental gallbladder cancer was found in $164(1.55 \%)$ patients. Patients with IGBC were significantly older than those having benign gallbladder pathology ( $59.23 \pm 12.17$ versus $45.73 \pm 13.11$ years, $p$-value $<0.001)$. Figures are in concordance with international literature as cancer usually affects elderly female in seventh/eighth decade while cholelithiasis is a disease of fourth decade [19]. Significantly more patients had concomitant disease in cancer group (p-value <0.001), higher ASA status (p-value <0.001) and larger stones ( $p$-value <0.001) conforming to reports of various other authors [20]. Acute cholecystitis (56.7\%) was most common presentation while anorexia was most frequent sinister symptom present in $32.3 \%$ of IGBC patients. Significantly more smokers with cancer were diagnosed as males ( $p$-value value <0.001). However, family history was more frequently found in female patients which may confer to more prevalence of gallstones in 
Table 3: Histopathological features of incidental gallbladder cancer with respect to gender

\begin{tabular}{|c|c|c|c|c|c|}
\hline \multirow[t]{2}{*}{ Characteristics } & \multicolumn{2}{|c|}{ Male } & \multicolumn{2}{|c|}{ Female } & \multirow[t]{2}{*}{ p-value } \\
\hline & Frequency & Percentage & Frequency & Percentage & \\
\hline \multicolumn{6}{|l|}{ Tumor type } \\
\hline Adenocarcinoma & 43 & 86 & 105 & 92.11 & \multirow{6}{*}{0.26} \\
\hline Adenosquamous & 3 & 6 & 5 & $4 \cdot 39$ & \\
\hline Undifferentiated & 2 & 4 & 2 & 1.75 & \\
\hline $\mathrm{SCC}$ & o & o & 2 & 1.75 & \\
\hline sarcoma & 1 & 2 & o & o & \\
\hline Melanoma & 1 & 2 & o & o & \\
\hline \multicolumn{5}{|l|}{ Tumor Site } & \multirow{4}{*}{0.59} \\
\hline Body & 21 & 42 & 39 & 34.21 & \\
\hline Fundus & 20 & 40 & 49 & 42.98 & \\
\hline Neck & 9 & 18 & 26 & 22.81 & \\
\hline \multicolumn{5}{|l|}{ Wall of gallbladder } & \multirow{6}{*}{0.16} \\
\hline Normal & 9 & 18 & 22 & 19.30 & \\
\hline Thick contracted & 21 & 42 & 29 & 25.44 & \\
\hline Proximal & 1 & 2 & 11 & 9.65 & \\
\hline Circumferential & 18 & 36 & 48 & 42.11 & \\
\hline Cystic duct margin & 1 & 2 & 4 & $3 \cdot 51$ & \\
\hline \multicolumn{5}{|l|}{ Type of growth } & \multirow{4}{*}{0.47} \\
\hline Ulcerated & 17 & 34 & 50 & 43.86 & \\
\hline Papillary & 16 & 32 & 29 & 25.44 & \\
\hline Polipoidal & 17 & 34 & 35 & 30.70 & \\
\hline \multicolumn{5}{|l|}{ Mucosa of gallbladder } & \multirow{4}{*}{0.68} \\
\hline Normal & 15 & 30 & 27 & 23.68 & \\
\hline Ulcerated & 19 & 38 & 46 & 40.35 & \\
\hline Hemorrhagic & 16 & 32 & 41 & 35.96 & \\
\hline \multicolumn{5}{|l|}{ Grade of tumor } & \multirow{4}{*}{0.89} \\
\hline Well differentiated & 18 & 36 & 42 & 36.84 & \\
\hline Moderately differentiated & 14 & 28 & 35 & 30.70 & \\
\hline Poorly differentiated & 18 & 36 & 37 & 32.46 & \\
\hline \multicolumn{5}{|l|}{ Stage of the disease } & \\
\hline $\mathrm{I}$ & 12 & 24 & 22 & 19.3 & \\
\hline II & 13 & 26 & 25 & 21.93 & 0.72 \\
\hline III & 14 & 28 & 35 & 30.70 & \\
\hline IV & 11 & 22 & 32 & 28.07 & \\
\hline Second stage surgery & & & & & \\
\hline None & 10 & 20 & 21 & 18.42 & \\
\hline Radical/extended cholecystectomy & 5 & 10 & 15 & 13.58 & \\
\hline Whipple & 3 & 6 & 3 & 2.63 & 0.75 \\
\hline Palliation & 11 & 22 & 31 & 27.19 & \\
\hline Refused by patient & 21 & 42 & 44 & 38.60 & \\
\hline Invasion & & & & & \\
\hline Lymphovascular & 23 & 46 & 48 & 42.11 & 0.64 \\
\hline Perineural & 29 & 58 & 56 & 49.12 & 0.29 \\
\hline Liver & 23 & 46 & 63 & 55.26 & 0.27 \\
\hline Lymph node status & & & & & \\
\hline Not sent & 27 & 54 & 64 & 56.14 & \\
\hline$<3$ & 11 & 22 & 25 & 21.93 & 0.64 \\
\hline$>3$ & 4 & 8 & 10 & 8.77 & \\
\hline Negative & 8 & 16 & 15 & 13.16 & \\
\hline Resection margins & & & & & \\
\hline Positive & 10 & 20 & 34 & 29.82 & \\
\hline Negative & 25 & 50 & 47 & 41.23 & 0.39 \\
\hline Not mentioned & 15 & 30 & 33 & 28.95 & \\
\hline Immunohistochemistry & & & & & \\
\hline Yes & 21 & 42 & 44 & 38.60 & 0.68 \\
\hline No & 29 & 58 & 70 & 61.40 & \\
\hline
\end{tabular}


females worldwide. Majority of females were multipara (95.6\%). Simple cholecystectomy was most frequent operation performed while biopsy was performed in those having suspicion of malignancy peroperative. Histological diagnosis of malignancy was followed by staging investigations, discussion in MDT meeting and then treatment as per stage. Number of cases increased with advancing years which may be due to more surgeries being performed at our center. Histopathological analysis was performed in all specimens regardless of diagnosis as per guidelines [21].

Most common tumor found was adenocarcinoma (90.24\%) followed by adenosquamous carcinoma. Zhou et al. quoted that $93.1 \%$ patients in their series had adenocarcinoma [22]. Most of tumors in our series were well differentiated and fundus was most common site, the results are in concordance with study conducted by Cui et al. [23]. Majority of the patients had either stage II or stage III disease. Surprisingly, most of the patients (36.6\%) refused second stage surgery while radical cholecystectomy was most common definitive surgical procedure performed in 17 (10.37\%) patients. Other surgeries performed included pancreaticoduodenectomy in six, extended cholecystectomy in three and palliation in 42 patients. Simple cholecystectomy proved adequate in 31 patients. IHC was performed in $62(37.8 \%)$ patients to reach at diagnosis. Liver was the most common organ infiltrated by tumor. Lymph node analysis revealed that majority had either none sent or inadequate number which is also in concordance with international data [24]. Resection margins were found negative in majority (37.8\%), however, no comment was found in case of 48 (29.3\%) patients.

Our results are consistent with international figures quotes worldwide [25-27]. A study conducted by Zhou et al. [22] showed a frequency of $2.06 \%$ while another study by He et al. [12] revealed higher age but similar findings as for as stage and treatment strategies are concerned. Haq et al. [28] conducted a study at Fauji Foundation hospital, Rawalpindi, Pakistan and showed frequency of $0.68 \%$. A review performed by Piccolo et al. [24] showed that frequency of IGBC varied from $0.25-3 \%$. They also revealed that in most studies proper number of lymph nodes were either not resected or not sent which is case with our study as well. A meta-analysis involving 986 articles by Choi et al. [8] found that most important clinical dilemma with IGBC is decision of second stage surgery both at clinician as well as patient end. Same dilemma is visible in our series where majority of patients refused definitive surgery in spite of thorough counseling. Most of cancer patients had acute cholecystitis which is consistent with results quoted by You et al. [13]. Most of female cancer patients in our cohort were multipara as also reported by Chan et al. [29].

Incidental gallbladder cancer represent an important area of research as early diagnosis will considerably affect morbidity as well as mortality. Alterations in oncogenes, tumor suppressor genes, microsatellite instability and methylation of gene promoter areas act in synergy with recurrent or chronic mucosal inflammation to induce cancer although exact cause in not known [30]. Gallstones especially chronic one pose most significant risk although other suspected culprits [31] are advance age, female sex, positive family history, cholelithiasis, obesity (BMI > 30), parasitic infestations, chronic bacterial cholangitis especially by Salmonella and Helicobacter [32], porcelain gallbladder, large polyps $>10 \mathrm{~mm}$, heavy metals exposure and abnormal pancreaticobiliary duct junction [33] Clinical features are ominous but those harboring clue include persistent right upper quadrant pain, jaundice, nausea and weight loss [8]. Biochemical investigations are nonspecific. Ultrasound features that may give rise to suspicion include wall thickness $>3 \mathrm{~mm}$ and enhanced vascularity. Currently EUS along with fine needle aspiration cytology (FNAC) has become modality of choice to distinguish benign from malignant lesion and stage disease [34]. Computed tomography diagnostic features of GBC are heterogeneously enhanced wall area, irregular distorted gallbladder filled with mass and it determines accurately possibility of surgical resection (93\% for T stage). Multiplanar and 3D volume rendered CT is current addition to diagnostic battery [35]. All-in-one MRI protocol (MRCP, magnetic resonance angiography) quite accurately detects bile duct or vascular invasion, with sensitivity and specificity approaching $100 \%$. Diffusion-weighted imaging (DWI) is revolutionizing the use of MR [36]. PET/CT may have a promising role in the diagnosis of unsuspected metastases thus changing staging and treatment early in the disease course [37]. Although no current tumor marker is available but most promising is CA-242 which may be regarded as marker of early infiltration [38]. Histopathology is current gold standard for diagnosis and provides framework for future management options [21]. Staging is the most significant factor determining treatment and prognosis in short as well as long-term [39]. A minimum of three regional lymph nodes are required for accurate "N" staging while adequate clearance requires at least six as per SEER guidelines [3].

Surgery is the only cure available at present and options include simple cholecystectomy (stage 1/Tis, T1a), extended cholecystectomy (stage $1 / \mathrm{T} 1 \mathrm{~b}$ ), radical cholecystectomy (stage II/T2), major hepatic/ bile duct resection or pancreaticoduodenectomy (stage III/ $\mathrm{T}_{3}$ ) and palliation (surgical/nonsurgical) for stage IV disease $[27,40]$. Regional lymphadenectomy is a must but currently neglected part of oncological clearance [41]. Factors that may point towards sinister diagnosis during surgery include thick wall, stiff uneven pale surface, miliary nodules, enlarged regional lymph nodes, plastered atrophied gallbladder, intraluminal nodules/mass or local gallbladder wall thickening and necrotic tissue/blood clot found in gallbladder lumen [42]. There is still no effective adjuvant or neoadjuvant chemo radiotherapy for GBC although combination 
chemotherapies and targeted molecular therapies are rapidly emerging [43, 44].

The results of this study should be interpreted with care as it was single center study. Although small number of patients limited the accuracy of the study but low incidence of gallbladder cancer makes it difficult to acquire larger cohorts. Moreover, there was no data reported regarding results of definitive surgery and patient survival thus missing extremely important aspect. Larger multicenter studies are required to further extend the results of our work. Various aspects of IGBC like risk factors, tumor markers and survival rates need to be studied further. The results of current study will help us to identify at risk patients and formulate guidelines for appropriate surgical intervention in conjunction with oncologist/gastroenterologist feedback [45].

\section{CONCLUSION}

The clinical and radiologic diagnosis of gallbladder cancer at early stage is challenging despite recent advances in technology. A detailed clinical history, high index of suspicion, good ultrasonologist and competent histopathologist is the linchpin for early diagnosis. The surgical strategy and prognosis differ strikingly according to T-stage and Ro resection is still the only chance of cure. Interdisciplinary collaboration among surgeon, ultrasonologist, oncologist, endoscopy expert and histopathologist is hallmark of improved vigilance and better long term outcome. Prognosis is very ominous due to high recurrence, morbidity and mortality.

\section{$* * * * * * * * *$}

\section{Acknowledgements}

We are thankful to Dr Salman registrar histopathology and Dr Azhar for their kind support.

\section{Author Contributions}

Muhammad Tanveer Sajid - Substantial contributions to conception and design, Acquisition of data, Analysis and interpretation of data, Drafting the article, Revising it critically for important intellectual content, Final approval of the version to be published

Syed Mukarram Hussain - Substantial contributions to conception and design, Acquisition of data, Revising it critically for important intellectual content, Final approval of the version to be published

Shoaib Nayyar Hashmi - Substantial contributions to conception and design, Acquisition of data, Revising it critically for important intellectual content, Final approval of the version to be published

Qurat ul Ain Mustafa - Acquisition of data, Analysis and interpretation of data, Drafting the article, Final approval of the version to be published

Neelofar Shaheen - Acquisition of data, Revising it critically for important intellectual content, Final approval of the version to be published

\section{Guarantor}

The corresponding author is the guarantor of submission.

\section{Conflict of Interest}

Authors declare no conflict of interest.

\section{Copyright}

(C) 2017 Muhammad Tanveer Sajid et al. This article is distributed under the terms of Creative Commons Attribution License which permits unrestricted use, distribution and reproduction in any medium provided the original author(s) and original publisher are properly credited. Please see the copyright policy on the journal website for more information.

\section{REFERENCES}

1. Latorre SG, Ivanovic-Zuvic SD, Corsi SÓ, et al. Coverage of the gallbladder cancer prevention strategy in Chile: Results from the 2009-2010 national health survey. [Article in Spanish]. Rev Med Chil 2015 Feb;143(2):158-67.

2. Hundal R, Shaffer EA. Gallbladder cancer: Epidemiology and outcome. Clin Epidemiol $2014 \mathrm{Mar}$ 7;6:99-109.

3. Surveillance, Epidemiology and End-Results (SEER) Program. The Four Most Common Cancers for Different Ethnic Populations 2013. Bethesda, Maryland: National Cancer Institute, 2013.

4. Ghosh N, Bandopadhyay R, Tirkey L, Das DK. Trend and pattern of various types of cancer with special reference to gall bladder cancer in north bengal medical college, west bengal, India: A 3 years record based study. Int J Prev Med 2015 Mar 24;6:24.

5. Wernberg JA, Lucarelli DD. Gallbladder cancer. Surg Clin North Am 2014 Apr;94(2):343-60.

6. Solaini L, Sharma A, Watt J, Iosifidou S, Chin Aleong JA, Kocher HM. Predictive factors for incidental gallbladder dysplasia and carcinoma. J Surg Res 2014 Jun 1;189(1):17-21.

7. Dwivedi AN, Jain S, Dixit R. Gall bladder carcinoma: Aggressive malignancy with protean loco-regional and distant spread. World J Clin Cases 2015 Mar 16;3(3):231-44.

8. Choi KS, Choi SB, Park P, Kim WB, Choi SY. Clinical characteristics of incidental or unsuspected gallbladder cancers diagnosed during or after cholecystectomy: A systematic review and meta-analysis. World $\mathrm{J}$ Gastroenterol 2015 Jan 28;21(4):1315-23.

9. Ramos-Font C, Gómez-Rio M, Rodríguez-Fernández A, Jiménez-Heffernan A, Sánchez Sánchez R, Llamas-Elvira JM. Ability of FDG-PET/CT in the detection of gallbladder cancer. J Surg Oncol 2014 Mar;109(3):218-24.

10. Shindoh J, Vauthey JN. Staging of biliary tract and primary liver tumors. Surg Oncol Clin N Am 2014 Apr;23(2):313-22. 
11. Edge S, Byrd DR, Compton CC, Fritz AG, Greene FL, Trotti A. editors. AJCC Cancer Staging Manual. 7ed. New York: Springer-Verlag; 2010.

12. He XD, Li JJ, Liu W, et al. Surgical procedure determination based on tumor-node-metastasis staging of gallbladder cancer. World J Gastroenterol 2015 Apr 21;21(15):4620-6.

13. You Z, Ma WJ, Deng YL, et al. Histological examination of frozen sections for patients with acute cholecystitis during cholecystectomy. Hepatobiliary Pancreat Dis Int 2015 Jun;14(3):300-4.

14. Rakic M, Patrlj L, Kopljar M, et al. Gallbladder cancer. Hepatobiliary Surg Nutr 2014 Oct;3(5):221-6.

15. D'Hondt M, Lapointe R, Benamira Z, et al. Carcinoma of the gallbladder: Patterns of presentation, prognostic factors and survival rate. An 11-year single centre experience. Eur J Surg Oncol 2013 Jun;39(6):54853.

16. Pitt SC, Jin LX, Hall BL, Strasberg SM, Pitt HA. Incidental gallbladder cancer at cholecystectomy: When should the surgeon be suspicious? Ann Surg 2014 Jul;260(1):128-33.

17. Kai K, Aishima S, Miyazaki K. Gallbladder cancer: Clinical and pathological approach. World J Clin Cases 2014 Oct 16;2(10):515-21.

18. Koshenkov VP, Koru-Sengul T, Franceschi D, Dipasco PJ, Rodgers SE. Predictors of incidental gallbladder cancer in patients undergoing cholecystectomy for benign gallbladder disease. J Surg Oncol 2013 Feb;107(2):118-23.

19. Rammohan A, Cherukuri SD, Sathyanesan J, Palaniappan R, Govindan M. Incidental gall bladder cancers: Are they truly incidental? World $\mathrm{J}$ Gastrointest Oncol 2014 Dec 15;6(12):441-3.

20. Pilgrim $\mathrm{CH}$, Groeschl RT, Christians KK, Gamblin TC. Modern perspectives on factors predisposing to the development of gallbladder cancer. HPB (Oxford) 2013 Nov;15(11):839-44.

21. Deng YL, Xiong XZ, Zhou Y, Shrestha A, Li FY, Cheng NS. Selective histology of cholecystectomy specimensis it justified? J Surg Res 2015 Jan;193(1):196-201.

22. Zhu JQ, Han DD, Li XL, Kou JT, Fan H, He Q. Predictors of incidental gallbladder cancer in elderly patients. Hepatobiliary Pancreat Dis Int 2015 Feb;14(1):96-100.

23. Cui HX, Ma XD, Han XL, Zhang XH. Surgical strategies for unexpected gallbladder carcinoma. Eur Rev Med Pharmacol Sci 2014 Oct;18(20):3045-7.

24. Piccolo G, Di Vita M, Cavallaro A, et al. Lymph node evaluation in gallbladder cancer: Which role in the prognostic and therapeutic aspects. Update of the literature. Eur Rev Med Pharmacol Sci 2014 Dec;18(2 Suppl):47-53.

25. Clemente G, Nuzzo G, De Rose AM, et al. Unexpected gallbladder cancer after laparoscopic cholecystectomy for acute cholecystitis: A worrisome picture. J Gastrointest Surg 2012 Aug;16(8):1462-8.

26. Behari A, Kapoor VK. Incidental gall bladder cancer. Adv Surg 2013;47:227-49.

27. Yi X, Long X, Zai H, Xiao D, Li W, Li Y. Unsuspected gallbladder carcinoma discovered during or after cholecystectomy: Focus on appropriate radical reresection according to the T-stage. Clin Transl Oncol 2013 Aug;15(8):652-8.
28. Haq N, Khan BA, Imran M, Akram A, Jamal AB, Bangash F. Frequency of gall bladder carcinoma in patients with acute and chronic cholecystitis. J Ayub Med Coll Abbottabad 2014 Apr-Jun;26(2):191-3.

29. Chan TF, Wu CH, Chiu HF, Yang CY. Parity and risk of death from gallbladder cancer among a cohort of premenopausal parous women in Taiwan. Int $\mathrm{J}$ Environ Res Public Health 2015 Feb 5;12(2):1864-73.

30. Kumari N, Corless CL, Warrick A, et al. Mutation profiling in gallbladder cancer in Indian population. Indian J Pathol Microbiol 2014 Jan-Mar;57(1):9-12.

31. Jain K, Sreenivas V, Velpandian T, Kapil U, Garg PK. Risk factors for gallbladder cancer: A case-control study. Int J Cancer 2013 Apr 1;132(7):1660-6.

32. Segura-López FK, Güitrón-Cantú A, Torres J. Association between Helicobacter spp. infections and hepatobiliary malignancies: A review. World J Gastroenterol 2015 Feb 7;21(5):1414-23.

33. Pilgrim CH, Groeschl RT, Turaga KK, Gamblin TC. Key factors influencing prognosis in relation to gallbladder cancer. Dig Dis Sci 2013 Sep;58(9):245562.

34. Kim HJ, Lee SK, Jang JW, et al. Diagnostic role of endoscopic ultrasonography-guided fine needle aspiration of gallbladder lesions. Hepatogastroenterology 2012 Sep;59(118):1691-5.

35. Dwivedi AN, Pandey M, Shukla RC, Shukla VK, Gaharwar S, Maurya BN. Biological behavior and disease pattern of carcinoma gallbladder shown on 64-slice CT scanner: A hospital-based retrospective observational study and our experience. Indian $\mathrm{J}$ Cancer 2012 Jul-Sep;49(3):303-8.

36. Tan $\mathrm{CH}$, Lim KS. MRI of gallbladder cancer. Diagn Interv Radiol 2013 Jul-Aug;19(4):312-9.

37. Rakic M, Patrlj L, Kopljar M, et al. Gallbladder cancer. Hepatobiliary Surg Nutr 2014 Oct;3(5):221-6.

38. Wang YF, Feng FL, Zhao XH, et al. Combined detection tumor markers for diagnosis and prognosis of gallbladder cancer. World J Gastroenterol 2014 Apr 14;20(14):4085-92.

39. Hu L, Wang B, Liu X, Lv Y. Unsuspected gallbladder cancer: A clinical retrospective study. Arch Iran Med 2013 Nov;16(11):631-5.

40. Tamura S, Sugawara Y. Hepatobiliary surgery: The past, present, and future learned from Professor Henri Bismuth. Hepatobiliary Surg Nutr 2014 Feb;3(1):556.

41. Liu GJ, Li XH, Chen YX, Sun HD, Zhao GM, Hu SY. Radical lymph node dissection and assessment: Impact on gallbladder cancer prognosis. World $\mathrm{J}$ Gastroenterol 2013 Aug 21;19(31):5150-8.

42. Wang RT, Xu XS, Liu J, Liu C. Gallbladder carcinoma: Analysis of prognostic factors in 132 cases. Asian Pac J Cancer Prev 2012;13(6):2511-4.

43. Caldow Pilgrim CH, Groeschl RT, Quebbeman EJ, Gamblin TC. Recent advances in systemic therapies and radiotherapy for gallbladder cancer. Surg Oncol 2013 Mar;22(1):61-7.

44. Marino D, Colombi F, Ribero D, Aglietta M, Leone F. Targeted agents: How can we improve the outcome in biliary tract cancer? Hepatobiliary Surg Nutr 2013 Feb;2(1):31-3.

45. Boutros C, Gary M, Baldwin K, Somasundar P. Gallbladder cancer: Past, present and an uncertain future. Surg Oncol 2012 Dec;21(4):e183-91. 
Access full text article on other devices

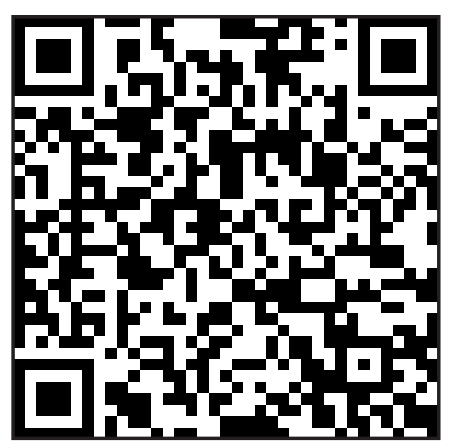

Access PDF of article on other devices

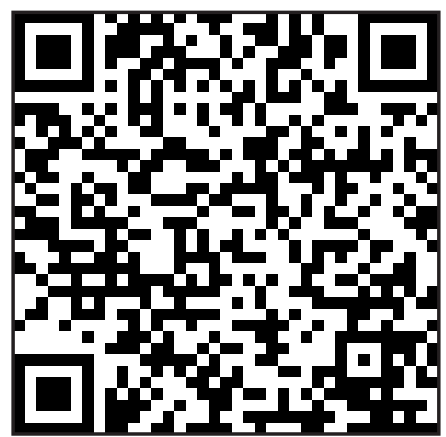

